doi:10.4149/neo_2015_091

\title{
Association of BCSC-1 with human esophageal squamous cell carcinoma
}

\author{
C. L. ZHAO ${ }^{1}$, W. J. YU 1 , Z. Q. GAO ${ }^{1}$, W. T. $\mathrm{LI}^{2}$, W. GAO ${ }^{2}$, W. W. YANG ${ }^{1}$, W. G. FENG ${ }^{1}$, J. Y. JU $U^{2, \star}$ \\ ${ }^{1}$ College of Pharmacy and Biological Science, ${ }^{2}$ College of Basic Medicine, Weifang Medical University, Weifang, China \\ ${ }^{*}$ Correspondence: juimmu@163.com
}

Received January 13, 2015 / Accepted May 25, 2015

\begin{abstract}
Breast cancer suppressor candidate-1 (BCSC-1) is a newly identified candidate tumor suppressor gene. BCSC-1 shows decreased levels in a variety of cancer types. In this study, we investigated the association between BCSC-1 and human esophageal squamous cell carcinoma (ESCC). BCSC-1 expression was detected in ESCC and normal tissues adjacent to tumor tissues by Western blot analysis and real-time PCR as well as immunohistochemistry of paraffin sections. The relationships between BCSC-1 expression and various clinicopathological characteristics were analyzed. Western blot analysis and real-time PCR showed that levels of BCSC-1 protein and mRNA expression in ESCC significantly decreased compared with those in adjacent normal tissues. Immunohistochemistry exhibited marked reduction of BCSC-1 in 38 of 105 ESCC specimens. Moreover, downregulation of BCSC-1 was associated with the grade of tumor cellular differentiation $(P<0.05)$. These findings indicate that BCSC-1 downregulation in ESCC is associated with carcinogenesis and may play important roles during the process of ESCC cancer development.
\end{abstract}

Key words: BCSC-1, ESCC, immunohistochemistry

Esophageal cancer is one of the most aggressive malignancies and the sixth leading cause of cancer deaths worldwide [1]. Esophageal squamous cell carcinoma (ESCC) is the most common histological form of esophageal cancer. The disease is characterized by regional variations in incidence. Over $50 \%$ of all ESCC cases reported worldwide occurred in China. Despite tremendous advances in diagnostic techniques and therapeutic methods, ESCC remains a devastating malignancy because of late diagnoses and its aggressive nature. Therefore, early diagnosis and targeted therapy are essential to understand the molecular aberrations involved in the occurrence and development of ESCC.

Inactivation of tumor suppressor genes (TSG) and activation of oncogenes have been observed in ESCC occurrence and development. Molecular studies have also revealed frequent genetic abnormalities, such as p53 mutations, loss of p16MAT1 and/or p15 expression, reduced Rb expression, amplification of cyclinD1, elevations in c-myc, COX-2 expression, cytoplasmic $\beta$-catenin level [2], and inactivation of GSK3 3 [3]. Moreover, altered expression of some growth- or differentiation-related genes has been associated with ESCC $[4,5]$. However, these observations are insufficient to understand the common pathways of carcinogenesis and malignant development of ESCC, and the molecular mechanisms of this disease have yet to be convincingly identified.
The breast cancer suppressor candidate-1 (BCSC-1, NM_014622) gene is a newly identified candidate tumor suppressor gene that is also called LOH11CR2 [6]. BCSC-1 is located at chromosome 11q23 and encodes a 786 amino acid protein with a predicted molecular mass of $86 \mathrm{kDa}$ containing two conserved domains, a vault protein inter-alpha-trypsin inhibitor domain at the $\mathrm{N}$-terminus and a von Willebrand factor type A domain at the C-terminus. However, the precise biological function of this protein is unknown. Several studies have shown that BCSC-1 is downregulated or lost in breast cancer-derived cells [6], lung adenocarcinoma [7], nasopharyngeal carcinoma [8], cervical carcinoma [9], and melanoma [10]. These data indicate that aberrant expression of BCSC-1 may lead to tumorigenesis. Nevertheless, the relationship between BCSC-1 expression and ESCC remains unclear.

In the present study, we investigate BCSC-1 expression in ESCC by Western blot analysis, real-time PCR, and immunohistochemistry. Our study provides evidence of a correlation between BCSC-1 expression and ESCC.

\section{Materials and methods}

Tissue specimens. A total of 105 pathologically and clinically confirmed ESCC and adjacent histologically normal tissues were obtained from patients who did not receive any 
treatment before surgery at the affiliated hospital, Weifang Medical University, Weifang, China. Primary tumor regions and the corresponding histological normal esophageal mucosa from the same patients were separated by experienced pathologists and immediately stored at $-80{ }^{\circ} \mathrm{C}$ until use for immunohistochemistry, RNA isolation, or protein extraction. Samples were obtained and used with the written informed consent of the patients and approval of the institutional ethics committee.

Immunohistochemistry. Immunohistochemistry was carried out following procedures described previously [11]. Tissue samples were fixed in formalin and embedded in paraffin. Paraffin-embedded sections about $4 \mu \mathrm{m}$ thick were deparaffinized in xylene, rehydrated in graded ethanol, and incubated in $3 \%$ hydrogen peroxide in methanol to block endogenous peroxidase. Following antigen retrieval by microwaving in citrate buffer ( $\mathrm{pH}$ 6.0) for $20 \mathrm{~min}$, slides were incubated overnight with BCSC-1 monoclonal antibody (Santa Cruz, CA, USA) at 1:100 dilution and $4{ }^{\circ} \mathrm{C}$. The second (peroxidase) step was performed using the UltraSensitive Streptavidin-Peroxide Kit (Zhong Shan Golden Bridge, Beijing, China) according to the manufacturer's protocol. DAB and hematoxylin were used as the chromogen and counterstain, respectively. Sections were finally sealed with neutral resin.

Evaluation of immunohistochemical staining. The expression score of BCSC-1 was determined in terms of staining intensity and immunoreactive cell percentage. Staining

A

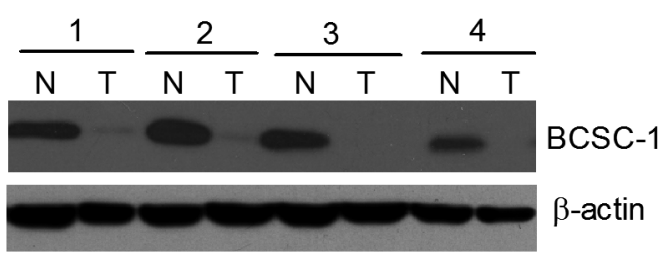

B



Figure 1. Downregulation of BCSC-1 in human esophageal squamous cell carcinoma. A: BCSC-1 expression was detected in ESCC tumors (T) and the corresponding normal epithelia $(\mathrm{N})$ by Western blot analysis using $\mathrm{mAb}$ anti-BCSC-1. The same blot was reprobed with $\mathrm{B}$-actin antibody as the loading control. B: The mRNA expression of BCSC-1 was examined in ESCC tumor and paired adjacent tissue samples by real-time PCR. The representative data are shown as the mean \pm SD of three independent experiments. ${ }^{*}, P<0.01$, compared with adjacent tissue samples. intensity was rated as follows: negative (0), bordering (1), weak (2), and strong (3). Staining extent was rated according to the percentage of positive cells in the field. Samples with no stained cells were rated as 0 , while those with $25 \%, 25 \%-50 \%$, and $50 \%$ stained cells were rated 1,2 , and 3 , respectively. The results of staining intensity and staining extent were used to obtain an overall staining score. Staining samples with scores of $0,1-2,3-4$, and 5-6 were marked $(-),( \pm),(+)$, and $(++)$, respectively. The evaluation criteria for BCSC-1 expression have been described previously [12].

Western blot analysis. The experiment was performed as described previously [13]. Whole cell extracts were prepared by homogenizing frozen ESCC tissue samples in lysis buffer $(10 \mathrm{mmol} / \mathrm{L}$ Tris- $\mathrm{HCl}$ [pH 7.5], $150 \mathrm{mmol} / \mathrm{L} \mathrm{NaCl}$, $1 \%$ NP40) containing a cocktail of protease inhibitors. After centrifugation, supernatants were collected and used for immunoblot analysis. The proteins were separated by SDSPAGE and subsequently transferred onto polyvinylidene difluoride membranes (Millipore, Bedford, MA, USA). Blots were blocked and probed with antibodies against BCSC-1 (1:500 dilution) and $\beta$-actin (1:5,000 dilution) (Santa Cruz). After washing, the blots were incubated with horseradish peroxidase-conjugated secondary antibodies and visualized by super ECL detection reagent (Applygen, Beijing, China).

RNA extraction and real-time PCR. Total RNAs from the frozen tissue specimens were extracted using Trizol reagent (Promega, Madison, USA), and cDNA was synthesized from 3-5 $\mu \mathrm{g}$ of RNA using reverse transcription reagents (Takara, Dalian, China) according to the manufacturer's directions. Real-time PCR assay was performed as described previously [14]. SYBR Premix Ex Tap (Takara) in an ABI Prism 7500 sequence detector (Applied Biosystems, Darmstadt, Germany) was used. The specific primer pairs used were as follows: BCSC-1: 5'-GGAATTCATGGTG CACTTCTGTGGCCT3' and 5'-GTCTAGAGCTCAAAAGGCAAAGATAGCAG3'. ß-actin: 5'-TGACGTGGACATCCGCAAAG-3' and 5'CTGGAAGGTGGACAGCG AGG-3' B-actin was applied as the input interference. The PCR cycling conditions included 35 cycles of denaturation at $95^{\circ} \mathrm{C}$ for $40 \mathrm{sec}$, annealing at 58 ${ }^{\circ} \mathrm{C}$ for $30 \mathrm{sec}$, and extension at $72{ }^{\circ} \mathrm{C}$ for $30 \mathrm{sec}$. The mean BCSC-1 level of the three real-time PCR experiments was calculated for each case. Results of the real-time PCR data are presented as $\mathrm{C}_{\mathrm{T}}$, which is defined as the threshold PCR cycle number at which an amplified product is first detected. The average $\mathrm{C}_{\mathrm{T}}$ was calculated for both BCSC-1 and $\mathrm{B}$-actin, and $\Delta \mathrm{C}_{\mathrm{T}}$ was determined as the mean of the triplicate $\mathrm{C}_{\mathrm{T}} \mathrm{s}$ for $\mathrm{BC}$ SC-1 minus the mean of the triplicate $\mathrm{C}_{\mathrm{T}}$ f for $\mathrm{B}$-actin. $\Delta \Delta \mathrm{C}_{\mathrm{T}^{2}}$ which represents differences between paired tissue samples, was calculated by the formula $\Delta \Delta \mathrm{C}_{\mathrm{T}}=\left(\Delta \mathrm{C}_{\mathrm{T}}\right.$ of tumor $-\Delta \mathrm{C}_{\mathrm{T}}$ of normal). The relative expression level (defined as fold change) of the target gene BCSC-1 $\left(2^{-\Delta \Delta C}\right.$ T $)$ was normalized to the endogenous $B$-actin reference and expressed relative to the amount of target gene in the control sample.

Statistical analysis. The relationship between BCSC-1 expression and clinicopathological characteristics was analyzed 

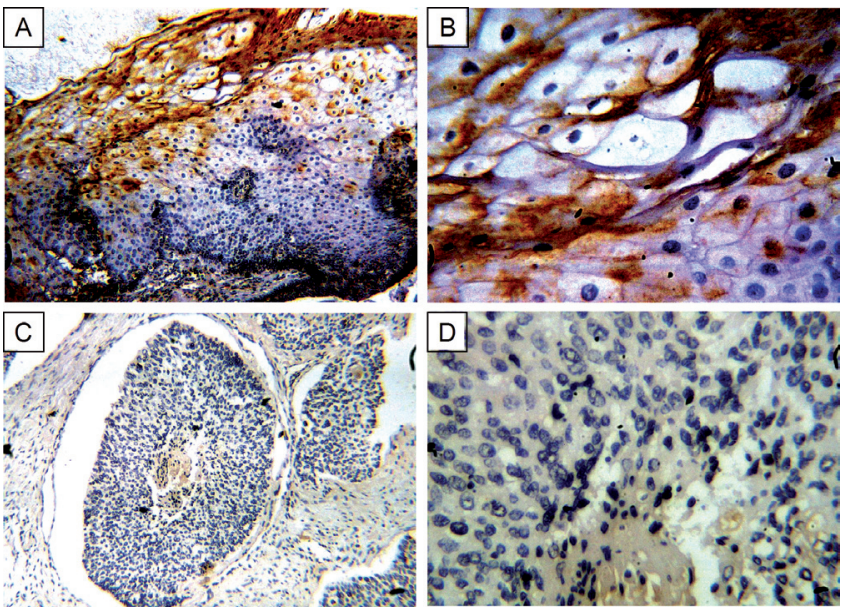

Figure 2. Immunohistochemical staining of BCSC-1. Localization and expression levels of BCSC-1 in ESCC tissue sections were detected using $\mathrm{mAb}$ anti-BCSC-1. A, B: Strong expression of BCSC-1 appears in the spinous layer of normal esophageal squamous epithelium. BCSC-1 is mainly localized in the cell membrane and cytoplasm in normal mucosa. C, D: Weak staining of BCSC-1 in ESCC. Magnification: $\times 100$ (left), $\times 400$ (right).

by $\chi^{2}$ tests with Statistical Package for Social Scientists software (SPSS, Inc., Chicago, IL, USA). $P<0.05$ was considered statistically significant.

\section{Results}

BCSC-1 protein and $\mathrm{mRNA}$ expression in ESCC. Whereas the high expression of BCSC-1 was detected in normal adjacent epithelia by Western blot analysis, BCSC-1 protein was downregulated to different degrees in ESCC (Fig. 1A). Consistent with the Western blot analysis results, real-time PCR showed that the levels of BCSC-1 mRNA expression were reduced more significantly $(P<0.01)$ in ESCC than in adjacent normal tissues (Fig. 1B).

Immunohistochemical analysis of BCSC-1 expression in ESCC. BCSC-1 expression in ESCC at the protein level was studied and compared with that of normal adjacent epithelia by immunohistochemical staining. BCSC-1 was highly expressed beyond the suprabasal level of normal esophageal squamous epithelium. The gene is mainly localized in the cell membrane and cytoplasm but can be observed in the nucleus in some individuals. BCSC-1 expression was remarkably reduced in ESCC tissues (Fig. 2). Table 1 shows the immunohistochemistry data. In adjacent normal tissues, the positive rate of BCSC-1 staining was $100 \%(105 / 105)$. BCSC-1 expression was downregulated more significantly in ESCC (36.2.0\%, $38 / 105)$ than in normal adjacent tissues $(P<0.0001)$.

BCSC-1 downregulation correlates with ESCC cellular differentiation. The association between BCSC-1 expression and degree of tumor differentiation was examined. As shown in Fig. 3, strong staining of BCSC-1 appeared in ESCC with good differentiation. ESCC tissues with moderate or poor
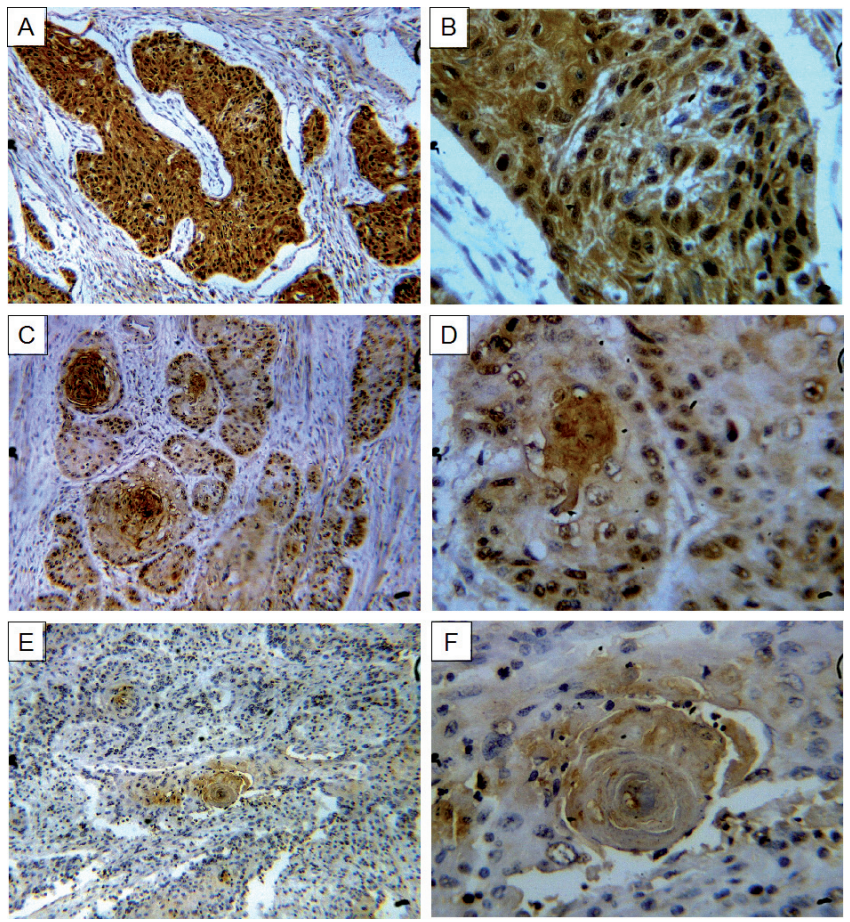

Figure 3. Expression BCSC-1 in ESCC tissues with different degrees of differentiation. A, B: Strong staining of BCSC-1 in ESCC with good differentiation. C, D: Heterogeneous cytoplasmic BCSC-1 expression in ESCC with moderate differentiation. E, F: Focal staining of BCSC-1 in ESCC with poor differentiation. Magnification: $\times 100$ (left), $\times 400$ (right).

Table1. Association of BCSC-1 downregulation with clinicopathologic features in ESCC

\begin{tabular}{|c|c|c|c|c|c|}
\hline \multirow{2}{*}{ Clinical features } & \multirow{2}{*}{ Total } & \multicolumn{3}{|c|}{ BCSC-1 expression } & \multirow{2}{*}{$P$-value } \\
\hline & & $(-) \operatorname{or}( \pm)$ & $(+)$ & $(++)$ & \\
\hline In general & & & & & $<0.0001$ \\
\hline Tumor tissue & 105 & 38 & 43 & 24 & \\
\hline Normal adjacent tissue & 105 & 0 & 0 & 105 & \\
\hline Gender & & & & & 0.2155 \\
\hline Male & 90 & 34 & 34 & 22 & \\
\hline Female & 15 & 4 & 9 & 2 & \\
\hline Age, $y$ & & & & & 0.1166 \\
\hline$\leq 60$ & 49 & 13 & 23 & 13 & \\
\hline$>60$ & 56 & 25 & 20 & 11 & \\
\hline Differentiation & & & & & $<0.0001$ \\
\hline Well & 21 & 3 & 5 & 13 & \\
\hline Moderate & 59 & 13 & 35 & 11 & \\
\hline Poor & 25 & 22 & 3 & 0 & \\
\hline Tumor invasion & & & & & 0.2070 \\
\hline $\mathrm{T} 1$ & 41 & 16 & 18 & 7 & \\
\hline $\mathrm{T} 2$ & 30 & 12 & 12 & 6 & \\
\hline $\mathrm{T} 3$ & 34 & 10 & 13 & 11 & \\
\hline Lymph node metastasis & & & & & 0.6774 \\
\hline No & 83 & 29 & 33 & 21 & \\
\hline N1 & 22 & 9 & 10 & 3 & \\
\hline Clinical stage & & & & & 0.7541 \\
\hline 0 and $\mathrm{I}$ & 40 & 16 & 18 & 6 & \\
\hline IIa and IIb & 56 & 18 & 21 & 17 & \\
\hline III & 9 & 4 & 4 & 1 & \\
\hline
\end{tabular}


differentiation exhibited lower expression levels of BCSC-1 protein than tumors with good differentiation $(P<0.0001)$. Table 1 summarizes the relevant data.

BCSC-1 expression and other clinicopathological features of ESCC. The correlation between BCSC-1 status and other ESCC clinicopathological features was evaluated. Results showed no significant correlation between BCSC-1 downregulation and patient gender, age, tumor invasion, lymph node metastasis, and clinical stage $(P>0.05)$.

\section{Discussion}

Martin et al. [6] first cloned BCSC-1 by constructing a physical map of the LOH11CR2 minimal region of loss on 11q23-q24 associated with lung and breast carcinoma and determined that BCSC-1 is a candidate tumor suppressor gene. This finding was subsequently verified by Zhou et al. [8] and Anghel et al. [10]: Zhou et al. found that BCSC-1 shows tumor suppressor functions in nasopharyngeal carcinoma, and Anghel et al. demonstrated that BCSC-1 is a melanoma tumor suppressor. Therefore, the accumulated evidence indicates that BCSC-1 is downregulated in a number of different cancer types.

In the present study, we demonstrated the downregulation of BCSC-1 in ESCC by Western blot analysis, real-time PCR, and immunohistochemistry. Approximately $36.2 \%$ of the ESCC samples exhibited marked reductions in BCSC-1 expression whereas all adjacent normal tissues showed BCSC-1 expression. Interestingly, the decreased expression of BCSC-1 was associated with the grade of ESCC differentiation. Thus, inactivation of the BCSC-1 gene may contribute to the occurrence and progression of ESCC. To investigate this possibility, function experiments on ESCC cells and explorations of the related molecular mechanisms must be performed in the near future.

Little is known about the cellular function and related molecular mechanism of BCSC-1 involved in tumorigenesis. Tumorigenesis is a very complicated process regulated by a number of factors [15-20]. TSG has been found to exhibit multiple inhibitive effects on tumorigenesis [21-23]. Although BCSC-1 has been identified as a candidate tumor suppressor gene, its biological function in cancer is largely unknown. BCSC-1 is located at chromosome 11q23-q24, which is lost in a significant number (39\%) of primary breast cancer cells [24]. Deletion of this chromosomal region and/or hypermethylation of the BCSC-1 promoter may also be observed in lung adenocarcinoma [7], nasopharyngeal carcinoma [8], and cervical carcinoma [9]. The BCSC-1 gene has been shown to reside at a locus that is likely to harbor tumor-suppressor genes in cutaneous malignant melanoma [25].

To explore the molecular mechanism by which BCSC-1 influences cancer development and progression, several studies have focused on the interaction between BCSC-1 and the signal transduction pathway. Ectopic BCSC-1 in nasopharyngeal carcinoma cells results in enhanced cell aggregation associated with increased expression of E-cadherin/a-catenin, and BCSC- 1 suppression promotes Wnt signaling [8]. BCSC-1 expression decreases in human metastatic melanoma, and its ectopic expression in metastatic melanoma-derived cell lines blocks tumor formation in vivo as well as melanoma cell proliferation in vitro while increasing cell migration. BCSC-1 binds to Sox10, which downregulates MITF, thereby resulting in a switch of melanoma cells from a proliferative phenotype to a migratory phenotype. Therefore, BCSC-1 is a novel regulator of the MITF pathway [10]. Taking the results together, BCSC-1 downregulation may contribute to tumorigenesis and malignant progression of ESCC by altering the properties of cell aggregation, proliferation, and /or migration. These previous studies also indicate that a better understanding of the molecular mechanism of BCSC-1 would provide a novel therapeutic strategy for treating patients with cancer.

In summary, we have demonstrated that BCSC-1 is downregulated in human esophageal squamous cell carcinoma compared with that in adjacent normal tissue. Downregulation of BCSC-1 is associated with the grade of ESCC differentiation. Our study presents important information on the role of BCSC-1 in ESCC. BCSC-1 may serve as a novel molecular target for diagnosing and treating ESCC. Further study is necessary to elucidate the molecular mechanisms of BCSC-1 functions in esophageal neoplastic transformation and development.

Acknowledgments: This work was financially supported by the National Natural Science Foundation of China (30901779 and 81274093) and the Natural Science Foundation of Shandong Province, China (ZR2009CM019 and ZR2014HL058).

\section{References}

[1] JAMAL A, BRAY F, CENTER MM, FERLAY J, WARD E, FORMAN D. Global cancer statistics. CA Cancer J Clin 2011; 61: 69-90. doi: 10.3322/caac.20107 http://dx.doi.org/10.3322/ caac. 20107

[2] STONER GD, GUPTA A. Etiology and chemoprevention of esophageal squamous cell carcinoma. Carcinogenesis 2001; 22: 1737-1746. doi: 10.1093/carcin/22.11.1737 http://dx.doi. org/10.1093/carcin/22.11.1737

[3] PACCEZ JD, DUNCAN K, VAVA A, CORREA RG, LIBERMANN TA et al. Inactivation of GSK3 $\beta$ and activation of NF- $\kappa B$ pathway via Axl represents an important mediator of tumorigenesis in Oesophageal Squamous Cell Carcinoma. Mol Biol Cell 2015 Jan 7. pii: mbc.E14-04-0868. [Epub ahead of print]

[4] WANG Q, LU J, YANG C, WANG X, CHENG L et al. CASK and its target gene Reelin were co-upregulated in human esophageal carcinoma. Cancer Lett 2002; 179: 71-77. doi: 10.1016/S0304-3835(01)00846-1 http://dx.doi.org/10.1016/ S0304-3835(01)00846-1

[5] ZHANG Y, FENG YB, SHEN XM, CHEN BS, DU XL et al. Exogenous expression of Esophagin/SPRR3 attenuates the 
tumorigenicity of esophageal squamous cell carcinoma cells via promoting apoptosis. Int J Cancer 2008; 122: 260-266. doi: 10.1002/ijc.23104 http://dx.doi.org/10.1002/ijc.23104

[6] MARTIN ES, CESARI R, PENTIMALLI F, YODER K, FISHEL $\mathrm{R}$ et al. The BCSC-1 locus at chromosome 11q23-q24 is a candidate tumor suppressor gene. Proc Natl Acad Sci U S A 2003; 100: 11517 -11522. doi: 10.1073/pnas.1934602100 http:// dx.doi.org/10.1073/pnas.1934602100

[7] RASIO D, NEGRINI M, MANENTI G, DRAGANI TA, CROCE CM. Loss of heterozygosity at chromosome 11q in lung adenocarcinoma: identification of three independent regions. Cancer research 1995; 55: 3988-3991.

[8] ZHOU YQ, CHEN SL, JU JY, SHEN L, LIU Y et al. Tumor suppressor function of BCSC-1 in nasopharyngeal carcinoma. Cancer Sci 2009; 100: 1817-1822. doi: 10.1111/j.1349-7006.2009.01261.x http://dx.doi.org/10.1111/ j.1349-7006.2009.01261.x

[9] MAZUMDER, INDRA D, MITRA S, SINGH RK, DUTTA $S$ et al. Inactivation of CHEK1 and EI24 are associated with the development of invasive cervical carcinoma: Clinical and prognostic implications. Int J Cancer 2011; 129: 1859-1871. doi: 10.1002/ijc.25849 http://dx.doi. org/10.1002/ijc. 25849

[10] ANGHEL SI, CORREA-ROCHA R, BUDINSKA E, BOLIGAN KF et al. Breast cancer suppressor candidate-1 (BCSC-1) is a melanoma tumor suppressor that down regulates MITF. Pigment Cell Melanoma Res 2012; 25: 482-487. doi: 10.1111/j.1755-148X. 2012.01018.x

[11] TONG T, ZHONG Y, KONG J, DONG L, SONG Y et al. Overexpression of Aurora-A contributes to malignant development of human esophageal squamous cell carcinoma. Clin Cancer Res 2004; 10: 7304-7310. doi: 10.1158/ 1078- 0432. CCR-04-0806

[12] ZHAO C, GONG L, LI W, CHEN L. Overexpression of Plk1 promotes malignant progress in human esophageal squamous cell carcinoma. J Cancer Res Clin Oncol 2010; 136: 9-16. doi: 10.1007/s00432-009-0630-4 http://dx.doi.org/10.1007/ s00432-009-0630-4

[13] FENG YB, LIN DC, SHI ZZ, WANG XC, SHEN XM et al. Overexpression of PLK1 is associated with poor survival by inhibiting apoptosis via enhancement of survivin level in esophageal squamous cell carcinoma. Int J Cancer 2009; 124: 578-588. doi: 10.1002/ijc.23990 http://dx.doi.org/10.1002/ ijc. 23990

[14] LIU YJ, MENG FT, WANG LL, ZHANG LF, CHENG XP, ZHOU JN. Apolipoprotein E influences melatonin biosynthesis by regulating NAT and MAOA expression in C6 cells. J Pineal Res 2012; 52:397-402. doi: 10.1111/j.1600-079X.2011.00954.x http://dx.doi.org/10.1111/j.1600-079X.2011.00954.X
[15] SEBASTIAN C. Tracking down the origin of cancer: metabolic reprogramming as a driver of stemness and tumorigenesis. Crit Rev Oncog 2014; 19: 363-382. doi: 10.1615/ CritRevOncog.2014011844 http://dx.doi.org/10.1615/CritRevOncog.2014011844

[16] CHEN F. Alternative RNA Structure-Coupled Gene Regulations in Tumorigenesis. Int J Mol Sci 2014; 16: 452-475. doi: 10.3390/ijms16010452 http://dx.doi.org/10.3390/ ijms 16010452

[17] MORIN A, LETOUZE E, GIMENEZ-ROQUEPLO AP, FAVIER J. Oncometabolites-driven tumorigenesis: From genetics to targeted therapy. Int J Cancer 2014; 135: 2237-2248. doi: 10.1002/ijc.29080 http://dx.doi.org/10.1002/ijc.29080

[18] CERDA C, SANCHEZ C, CLIMENT B, VAZQUEZ A, IRADI A et al. Oxidative stress and DNA damage in obesityrelated tumorigenesis. Adv Exp Med Biol 2014; 824: 5-17. doi: 10.1007/978-3-319-07320-0_2 http://dx.doi.org/10.1007/9783-319-07320-0 2

[19] GAO F, LIANG B, REDDY ST, FARIAS-EISNER R, SU X. Role of inflammation -associated microenvironment in tumorigenesis and metastasis. Curr Cancer Drug Targets 2014; 14: 30-45. doi: 10.2174/15680096113136660107 http://dx.doi. org/10.2174/15680096113136660107

[20] SHACKELFORD DB. Unravelling the connection between metabolism and tumorigenesis through studies of the liver kinase B1 tumour suppressor. J Carcinog 2013; 12: 16. doi: 10.4103/1477-3163.116323 http://dx.doi.org/10.4103/1477$\underline{3163.116323}$

[21] VOLODKO N, GORDON M, SALLA M, GHAZALEH HA, BAKSH S. RASSF tumor suppressor gene family: biological functions and regulation. FEBS Lett 2014; 588: 2671-2684. doi: 10.1016/j.febslet.2014.02.041 http://dx.doi.org/10.1016/j. febslet.2014.02.041

[22] LIONTOS M, PATERAS IS, EVANGELOU K, GORGOULIS VG. The tumor suppressor gene ARF as a sensor of oxidative stress. Curr Mol Med 2012; 12: 704-715. doi: 10.2174/ 156652412800792633

[23] SOLOMON H, BROSH R, BUGANIM Y, ROTTER V. Inactivation of the p53 tumor suppressor gene and activation of the Ras oncogene: cooperative events in tumorigenesis. Discov Med 2010; 9: 448-454.

[24] CARTER SL, NEGRINI M, BAFFA R, GILLUM, D R, ROSENBERG AL et al. Loss of heterozygosity at 11q22-q23 in breast cancer. Cancer Res 1994; 54: 6270-6274.

[25] HERBST RA, GUTZMER R, MATIASK F, MOMMERT S, CASPER $U$ et al. Identification of two distinct deletion targets at 11q23 in cutaneous malignant melanoma. Int J Cancer 1999; 80: 205-209. doi: 10.1002/(SICI)1097-0215 (19990118) 80: 2<205: : AID-IJC8> 3.0.CO; 2-J 